Supplementary Materials for

\title{
In-situ generated high-valent iron single-atom catalyst for efficient oxygen evolution
}

Zhirong Zhang ${ }^{1} \uparrow$, Chen Feng ${ }^{1} \uparrow$, Xiangyang $\mathrm{Li}^{1} \uparrow$, Chunxiao Liu ${ }^{1}$, Dongdi Wang ${ }^{1}$, Rui Si ${ }^{2}$, Jinong Yang ${ }^{1}$, Shiming Zhou ${ }^{1 *}$, Jie Zeng ${ }^{1 *}$

${ }^{1}$ Hefei National Laboratory for Physical Sciences at the Microscale, Key Laboratory of Strongly-Coupled Quantum Matter Physics of Chinese Academy of Sciences, National Synchrotron Radiation Laboratory, Key Laboratory of Surface and Interface Chemistry and Energy Catalysis of Anhui Higher Education Institutes, Department of Chemical Physics, University of Science and Technology of China, Hefei, Anhui 230026, P. R. China

${ }^{2}$ Shanghai Synchrotron Radiation Facility, Shanghai Institute of Applied Physics, Chinese Academy of Sciences, Shanghai 201204, P. R. China

*Corresponding author. E-mail: zhousm@ustc.edu.cn (S.Z.); zengj@ustc.edu.cn (J.Z.)

$\dagger$ These authors contributed equally to this work. 


\section{Experimental Details}

Chemicals. Zirconium chloride $\left(\mathrm{ZrCl}_{4}\right)$, 1,4-benzenedicarboxylic $\left(\mathrm{H}_{2} \mathrm{BDC}\right)$, N,N-dimethylformamide (DMF), acetic acid (HAc), hydrofluoric acid (HF), iron(III) chloride $\left(\mathrm{FeCl}_{3}\right)$, potassium hydroxide $(\mathrm{KOH})$, iron(II) sulfate heptahydrate $\left(\mathrm{FeSO}_{4} \cdot 7 \mathrm{H}_{2} \mathrm{O}\right)$, sodium hydroxide $(\mathrm{NaOH})$, hydrogen peroxide $\left(\mathrm{H}_{2} \mathrm{O}_{2}\right)$, methanol, isopropanol, commercial $\mathrm{IrO}_{2}$, commercial $\mathrm{Fe}_{2} \mathrm{O}_{3}$, and Nafion were purchased from Shanghai Chemical Reagent Company. All the other chemicals were of analytical grade and used as received without further purification. All aqueous solutions were prepared using deionized water with a resistivity of $18.2 \mathrm{M} \Omega \mathrm{cm}^{-1}$.

Synthesis of porous carbon. The porous carbon (P-C) support was synthesized using a previously-reported method ${ }^{[\mathrm{S} 1]}$. First, $10.49 \mathrm{mg}$ of $\mathrm{ZrCl}_{4}, 7.49 \mathrm{mg}$ of $\mathrm{H}_{2} \mathrm{BDC}, 10 \mathrm{~mL}$ of DMF, and $1.2 \mathrm{~mL}$ of HAc were added in a $20-\mathrm{mL}$ glass vial. Then the mixture was uniformly dispersed under ultrasonication for $30 \mathrm{~min}$. Next the vial was kept at $120{ }^{\circ} \mathrm{C}$ for $24 \mathrm{~h}$. The as-obtained product was centrifuged and washed with DMF and methanol for three times. Subsequently, the product was dried at $60{ }^{\circ} \mathrm{C}$ under vacuum overnight. Afterwards the dried white powder was heated to $700{ }^{\circ} \mathrm{C}$ in a tube furnace with a heating rate of $5{ }^{\circ} \mathrm{C} / \mathrm{min}$ and kept for $3 \mathrm{~h}$ under nitrogen atmosphere. After naturally cooling down to room temperature, black powder was collected. Then the black powder was dispersed in $15 \mathrm{~mL}$ of $\mathrm{H}_{2} \mathrm{O}$ containing 0.1 mol HF under magnetic stirring for $2 \mathrm{~h}$ to remove zirconium oxides. In the end, the product was washed with methanol and $\mathrm{H}_{2} \mathrm{O}$ for three times, followed by vacuum drying at $60{ }^{\circ} \mathrm{C}$ overnight.

Synthesis of $\mathbf{F e}_{1}(\mathbf{O H})_{\mathbf{x}} / \mathbf{P}-\mathbf{C}$. We used an anodic electrochemical deposition method for the synthesis of $\mathrm{Fe}_{1}(\mathrm{OH})_{\mathrm{x}} / \mathrm{P}-\mathrm{C}$. A linear sweep voltammetry method was applied to the electrochemical deposition in a standard three-electrode system (CHI 660E, Shanghai $\mathrm{CH}$ Instruments). A glassy carbon electrode with a diameter of $3 \mathrm{~mm}$ was used as the working electrode. $15 \mathrm{mg}$ of the as-prepared P-C was first dispersed in a mixture of $\mathrm{H}_{2} \mathrm{O}(0.78 \mathrm{~mL})$, isopropanol $(0.16 \mathrm{~mL})$, and Nafion $(60 \mu \mathrm{L})$ to form a homogeneous ink under vigorous stirring. Then $4 \mu \mathrm{L}$ of this ink was casted onto the glassy carbon electrode with a carbon yield loading of $0.85 \mathrm{mg} \mathrm{cm}^{-2}$. A carbon rod was used as the counter electrode. $\mathrm{An} \mathrm{Ag} / \mathrm{AgCl}$ electrode was used as the reference electrode. All potentials mentioned in this work were measured against the $\mathrm{Ag} / \mathrm{AgCl}$ electrode and converted to reversible hydrogen electrode (RHE) scale by $E$ (V vs RHE) 
$=E(\mathrm{~V} \mathrm{vs} \mathrm{Ag} / \mathrm{AgCl})+0.194 \mathrm{~V}+0.0591 \mathrm{pH} \mathrm{V}$. In the given equation, $0.194 \mathrm{~V}$ was calibrated with respect to the reversible hydrogen electrode (RHE). The calibration was carried out using a three-electrode system in a high-purity hydrogen saturated $0.5 \mathrm{M} \mathrm{H}_{2} \mathrm{SO}_{4}$ electrolyte. The $\mathrm{Ag} / \mathrm{AgCl}$ was used as the reference electrode. A Pt wire was used as the working electrode. Another Pt wire was used as the counter electrode. The calibration was conducted using a cyclic voltammetry method with a sweep rate of $1 \mathrm{mV} \mathrm{s}^{-1}$. The average of the two potentials at which the current crossed zero was taken to be the thermodynamic potential for the hydrogen electrode reactions. The working electrode was pretreated using a linear sweep method under a potential ranging from 1.10 to $1.80 \mathrm{~V}$ for twenty cycles. Then $100 \mu \mathrm{M} \mathrm{FeCl}_{3}$ was added into the electrolyte as the Fe precursor and the mixture was stirred for $10 \mathrm{~min}$. Later the deposition was carried out using the linear sweep method from $1.10 \mathrm{~V}$ to $1.80 \mathrm{~V}$ with a sweep rate of $5 \mathrm{mV} \mathrm{s}^{-1}$. This process was repeated for five times. After the deposition, the obtained sample was then washed with deionized water and used for later electrochemical measurements.

Synthesis of FeOOH. FeOOH were prepared by a previously reported method ${ }^{[\mathrm{S} 2]}$. Firstly, $2 \mathrm{~g}$ of $\mathrm{FeSO}_{4} \cdot 7 \mathrm{H}_{2} \mathrm{O}$ was dissolved in $20 \mathrm{~mL}$ of deionized water. Then $10 \mathrm{~mL}$ of $10 \mathrm{M} \mathrm{NaOH}$ solution was added into the above solution at $45{ }^{\circ} \mathrm{C}$ under $\mathrm{N}_{2}$ atomsphere. Next, $5 \mathrm{~mL}$ of $30 \% \mathrm{H}_{2} \mathrm{O}_{2}$ solution was added into the mixture. The as-obtained sample was then isolated by centrifugation and washed with ethanol for several time. Finally, the sample was dried overnight for later measurements.

XAFS measurements. XAFS spectra at Fe $K$-edge were obtained at the BL14W1 beam line of Shanghai Synchrotron Radiation Facility operated at 3.5 GeV under 'top-up' mode with a constant current of $220 \mathrm{~mA}$. The XAFS data were recorded under fluorescence mode with a 32-element Ge solid-state detector. The energy was calibrated according to the absorption edge of pure Fe foil. Athena and Artemis codes were used to extract the data and fit the profiles. For the XANES spectra, the experimental absorption coefficients as a function of energies $\mu(\mathrm{E})$ were processed by background subtraction and normalization procedures. We refer to this process as 'normalized absorption'. For the EXAFS, the Fourier-transformed (FT) data in $R$ space were analysed by applying the first shell approximation or metallic $\mathrm{Fe}$ model for the $\mathrm{Fe}-\mathrm{O}$ or $\mathrm{Fe}-\mathrm{Fe}$ shell, respectively. The passive electron factors, $S_{0}{ }^{2}$, were determined by fitting the experimental 
Fe foil data and fixing the Fe-Fe coordination number $(C N)$ to be 12, and then fixed for further analysis of the measured samples. The parameters that describe the local structure environment such as $C N$, bond distance $(R)$, and Debye-Waller $(D . W$.) factor around the absorbed atoms were allowed to vary during the fit process.

Electrochemical measurements. An electrochemical workstation (CHI 660E, Shanghai $\mathrm{CH}$ Instruments) was used to measure the electrocatalytic properties of the samples. The electrocatalytic measurements were conducted in a standard three-electrode system at room temperature. The glassy carbon electrode loaded with the as-obtained catalysts was used as the working electrode. $4 \mathrm{mg}$ of active carbon and $1 \mathrm{mg}$ of commercial $\mathrm{Fe}_{2} \mathrm{O}_{3}, \mathrm{FeOOH}$, or commercial $\mathrm{IrO}_{2}$ were first dispersed in a mixture of $\mathrm{H}_{2} \mathrm{O}(0.8 \mathrm{~mL})$, isopropanol $(0.16 \mathrm{~mL})$, and Nafion (40 $\mu \mathrm{L}$ ) to form a homogeneous ink under vigorous stirring. Then $4 \mu \mathrm{L}$ of this ink was casted onto the working electrode and dried naturally. A carbon rod was used as the counter electrode. $\mathrm{An} \mathrm{Ag} / \mathrm{AgCl}$ electrode was used as the reference electrode. The OER polarization curves were obtained using a linear sweep voltammetry method at a potential range from 1.10 to $1.80 \mathrm{~V}$ with a sweep rate of $5 \mathrm{mV} \mathrm{s}^{-1}$ in $1.0 \mathrm{M} \mathrm{KOH}$. The potentials were corrected to compensate for the effect of solution resistance, which were calculated by the following equation: $E_{i R \text {-corrected }}=E(\mathrm{~V}$ vs $\mathrm{RHE})-i R$, where $i$ is the current, and $R$ is the uncompensated ohmic electrolyte resistance. In $1.0 \mathrm{M} \mathrm{KOH}, R$ is measured to be $\sim 9 \Omega$ via high frequency alternating current impedance. During the measurement of Faradaic efficiency (FE) of $\mathrm{Fe}_{1}(\mathrm{OH})_{\mathrm{x}} / \mathrm{P}-\mathrm{C}$ for $\mathrm{O}_{2}$ production, the gaseous products were analyzed by gas chromatography. The measurement was conducted in an H-type cell containing 1.0 M KOH with the cathodic and anodic chamber separated by a membrane. The working electrode $\left(\mathrm{Fe}_{1}(\mathrm{OH})_{\mathrm{x}} / \mathrm{P}-\mathrm{C}\right)$ and reference electrode $(\mathrm{Ag} / \mathrm{AgCl})$ were placed in the anodic chamber. The counter electrode (carbon rod) was placed in the cathodic chamber. The measurement was conducted at a current density of $10 \mathrm{~mA}$ $\mathrm{cm}^{-2}$ for $140 \mathrm{~min}$. During the process, argon was continuously sparged into the anodic chamber with a flow rate of $20 \mathrm{sccm}$. The gaseous product from the anode was measured in real time by in-line gas chromatography. The calculation of TOF was based on the activity of the catalysts for per-active-site by the equation: $\mathrm{TOF}=(j \times A) /(4 \times F \times m)$. In the equation, $j$ is the current density at a given overpotential, $A$ is the geometric surface area of the electrode, $F$ is the Faraday constant, and $m$ is the moles of metals on the electrode. Mass activity was evaluated by 
normalizing the measured OER current densities against $\mathrm{Fe}$ mass loadings on the electrode measured by ICP-AES. Tafel slope $(b)$ was determined by fitting polarization curves data to the Tafel equation: $\eta=a+b \log |j|$, where $\eta$ is the overpotential for OER, $j$ is the current density at the given overpotential, $a$ and $b$ are defined as Tafel constants. Durability tests were conducted in galvanostatic mode at $10 \mathrm{~mA} \mathrm{~cm}$ at room temperature in $1.0 \mathrm{M} \mathrm{KOH}$ solution. Electrochemical impedance spectroscopy (EIS) measurements were conducted at $1.23 \mathrm{~V}$. The amplitude of the sinusoidal wave was $10 \mathrm{mV}$. The frequency scan range was $1000 \mathrm{kHz}-100 \mathrm{~Hz}$. Differential pulse voltammetry (DPV) curves were collected on glassy carbon electrode in Ar-saturated 1.0 M KOH. Pure FeOOH was used for DPV measurement without loading on active carbon. Between the initial potential and final potential, a potential pulse was applied with an amplitude of $50 \mathrm{mV}$, a pulse width of $50 \mathrm{~ms}$, and an increment potential of $4 \mathrm{mV}$. Currents were sampled before the potential pulse and at the end of the pulse with a sampling width of 16.7 ms.

DFT calculations. First-principle calculations were performed using a spin-polarized DFT method within the Perdew-Burke-Ernzerholf (PBE) generalized gradient approximation $(\mathrm{GGA})^{[\mathrm{S} 3, \mathrm{~S} 4]}$ implemented in Vienna ab initio Simulation Package (VASP) ${ }^{[\mathrm{S} 5, \mathrm{~S} 6]}$. The projected augmented wave (PAW) method ${ }^{[\mathrm{S7}, \mathrm{S8}]}$ was used by plane-wave basis with a kinetic cutoff energy of $400 \mathrm{eV}$. A vacuum layer of about $15 \AA$ was adopted along the $z$-axis for all the slab models to avoid periodic image interactions. Both the lattice constants and positions of all atoms are fully relaxed until the force was smaller than $0.02 \mathrm{eV} / \AA$. The convergence criterion for the total energy is set to $1 * 10^{-5} \mathrm{eV}$. In order to study the mechanistic chemistry of surface reactions reasonably, an $8 * 5$ supercell was built for graphene carbon and a $4 * 4$ supercell was used for pure FeOOH (001) surface. For the FeOOH (001) surface, the slab model was derived from a previous study ${ }^{[S 9]}$ and used three feroxyhyte layers with each layer containing $17 \mathrm{Fe}$ atoms. Considering the possible van der Waals interaction between different $\mathrm{FeOOH}$ layers, the DFT-D3 semi-empirical method of Grimme ${ }^{[\mathrm{S} 10]}$ was adopted, which was expected to improve the accuracy of the predicted geometric and electronic structures of the system. For the geometric optimization calculations, all the atoms except those in the bottom two $\mathrm{FeOOH}$ layers were fully relaxed. Because of the large size of the unit cell and the limited computational resources, the Brillouin zone was sampled with the $\Gamma$ point only. 
The overpotentials were evaluated using the approach proposed by Nørskov and co-workers ${ }^{\left[{ }^{11}\right]}$. The following four-step reaction mechanism was considered in our calculations ${ }^{[\mathrm{S} 12]}$.

$$
\begin{aligned}
& \mathrm{OH}^{-}+* \rightarrow * \mathrm{OH}+\mathrm{e}^{-} \\
& * \mathrm{OH}+\mathrm{OH}^{-} \rightarrow * \mathrm{O}+\mathrm{H}_{2} \mathrm{O}(\mathrm{l})+\mathrm{e}^{-} \\
& * \mathrm{O}+\mathrm{OH}^{-} \rightarrow * \mathrm{OOH}+\mathrm{e}^{-} \\
& * \mathrm{OOH}+\mathrm{OH}^{-} \rightarrow *+\mathrm{O}_{2}(\mathrm{~g})+\mathrm{H}_{2} \mathrm{O}(\mathrm{l})+\mathrm{e}^{-}
\end{aligned}
$$

where $*$ represents the active site for intermediates. The Gibbs free energy changes were calculated by

$$
\Delta G_{i}=\Delta E_{i}+\Delta \mathrm{ZP} E_{i}-T \Delta S_{i}
$$

Here, $i=1,2,3,4$ corresponds to the four steps of reactions (1) to (4). $\Delta E_{i}$ is the reaction energy, $\triangle \mathrm{ZP} E_{i}$ and $\Delta S_{i}$ are the change of zero-point energy and vibrational entropy at $298.15 \mathrm{~K}$, respectively.

The theoretical OER overpotential is defined as:

$$
\eta_{\mathrm{OER}}=\left[\left(\max \left(\Delta G_{i}\right) / e\right]-1.23 \mathrm{~V}\right.
$$

in which $\max \left(\Delta G_{i}\right)$ is the potential determining step in the process of OER and $e$ is unit charge.

Instrumentations. TEM images were taken on Hitachi H-7650 transmission electron microscope operating at an acceleration voltage of $100 \mathrm{kV}$. X-ray diffraction (XRD) patterns were recorded using a Philips X'Pert Pro Super diffractometer with $\mathrm{Cu}-\mathrm{K} \alpha$ radiation $(\lambda=$ $1.54178 \AA$ ). Raman spectrum were collected using a laser Raman analyzer LabRAM HR (Horiba/Jobin Yvon, Longjumeau) equipped with a frequency doubled Nd:YAG $532.1 \mathrm{~nm}$ laser. HAADF-STEM images and energy-dispersive X-ray elemental mapping were carried out on JEOL ARM-200F field-emission transmission electron microscope operating at an accelerating voltage of $200 \mathrm{kV}$ using Cu-based TEM grids. XPS measurements were performed on a VG ESCALAB MK II X-ray photoelectron spectrometer with $\mathrm{Mg} \mathrm{K \alpha}=1253.6 \mathrm{eV}$ as the exciting source. ICP-AES (Atomscan Advantage, Thermo Jarrell Ash, USA) analyses were used to determine the mass loadings of metal species. The gas products of OER were monitored by an 
online GC (SHIMADZU, GC-2014) equipped with a TCD detector and Molsieve 5A colum. XAS spectra (C $K$-edge) were measured at the beamline $12 \mathrm{~B}$ of national synchrotron radiation laboratory (NSRL, Hefei). Ultraviolet-visible (UV-vis) adsorption spectrum was conducted on UV-vis spectrophotometer (Agilent Technologies, Cary 60).

Data availability. The data that supports the findings of this study are available from the corresponding author on request. 

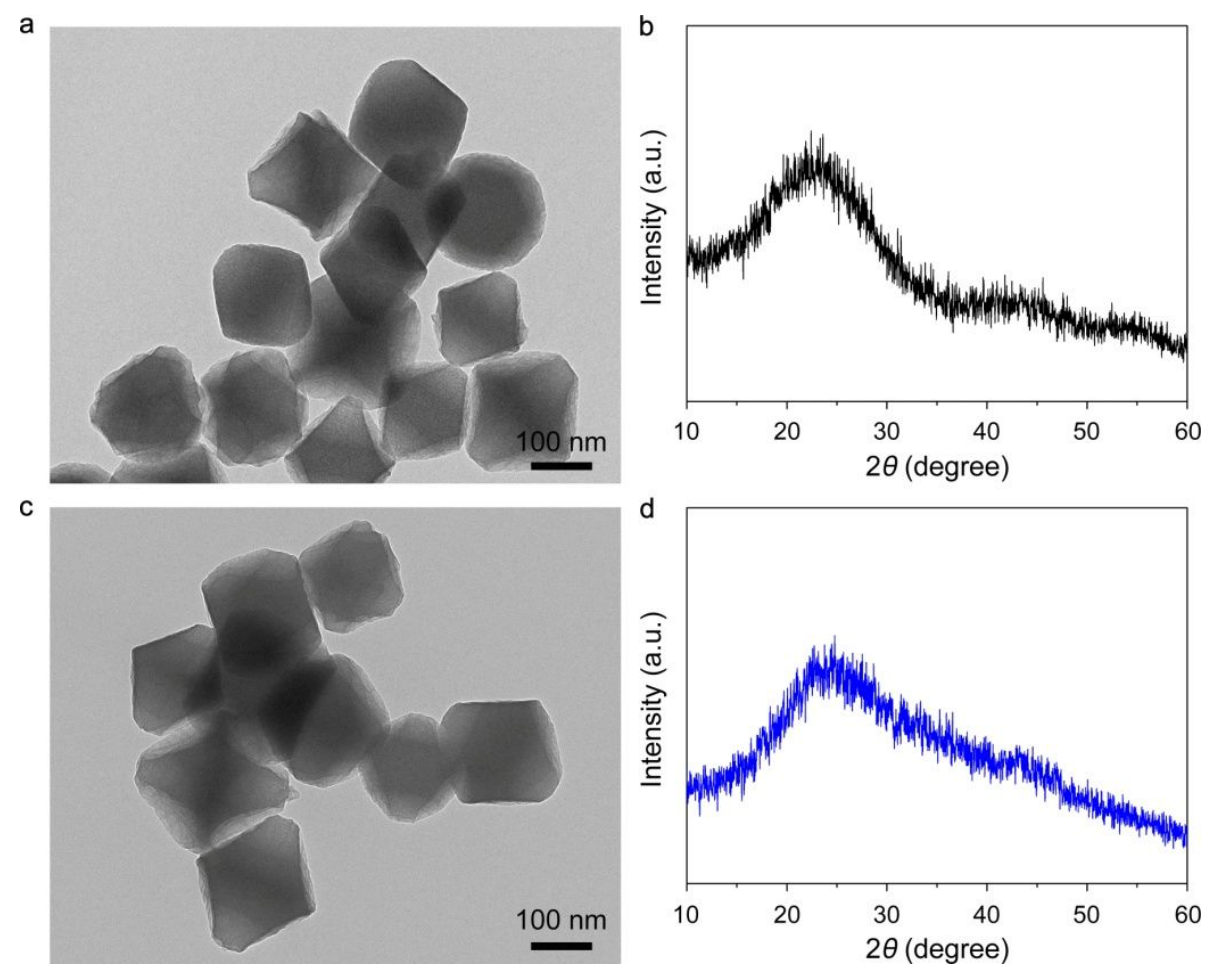

Figure S1. Morphological and structural characterizations of $\mathrm{P}-\mathrm{C}$ and $\mathrm{Fe}_{1}(\mathrm{OH})_{\mathrm{x}} / \mathrm{P}-\mathrm{C} . \mathrm{a}, \mathrm{b}$, TEM image (a) and XRD pattern (b) of P-C. c, d, TEM image (c) and XRD pattern (d) of $\mathrm{Fe}_{1}(\mathrm{OH})_{\mathrm{X}} / \mathrm{P}-\mathrm{C}$. 


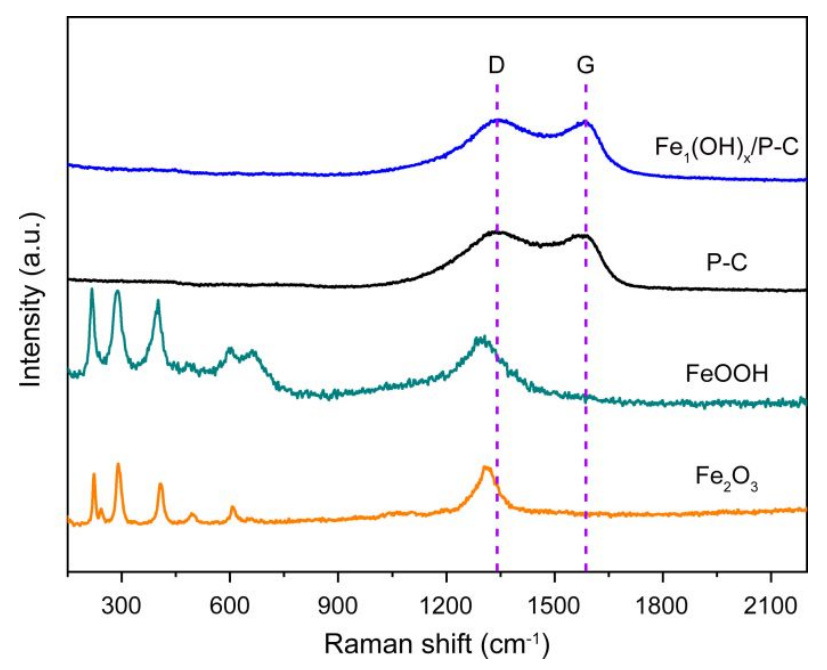

Figure S2. Raman spectrum of $\mathbf{P}-\mathbf{C}$ and $\mathbf{F e}_{1}(\mathbf{O H})_{\mathbf{x}} / \mathbf{P}-\mathbf{C}$. The two peaks at 1350 and $1580 \mathrm{~cm}^{-1}$ respond to the characteristic D- and G-band of carbon, respectively. The Raman spectra of $\mathrm{FeOOH}$ and $\mathrm{Fe}_{2} \mathrm{O}_{3}$ were used for reference. No peaks attributed to Fe-based oxides or hydroxides were discerned in $\mathrm{Fe}_{1}(\mathrm{OH})_{\mathrm{x}} / \mathrm{P}-\mathrm{C}$, suggesting their absence. 

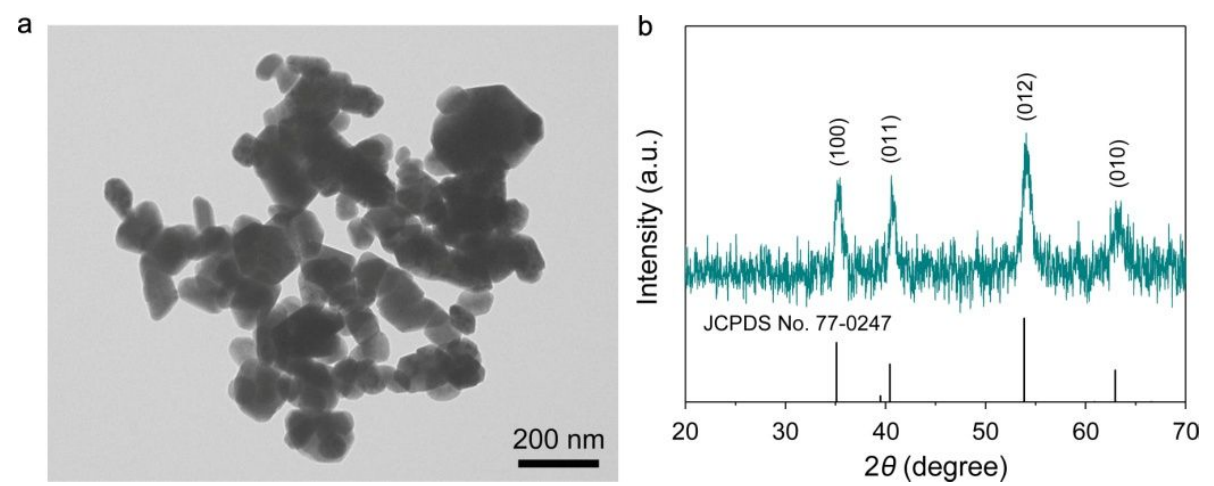

Figure S3. Morphological and structural characterizations of FeOOH. a, TEM image. b, XRD pattern. 

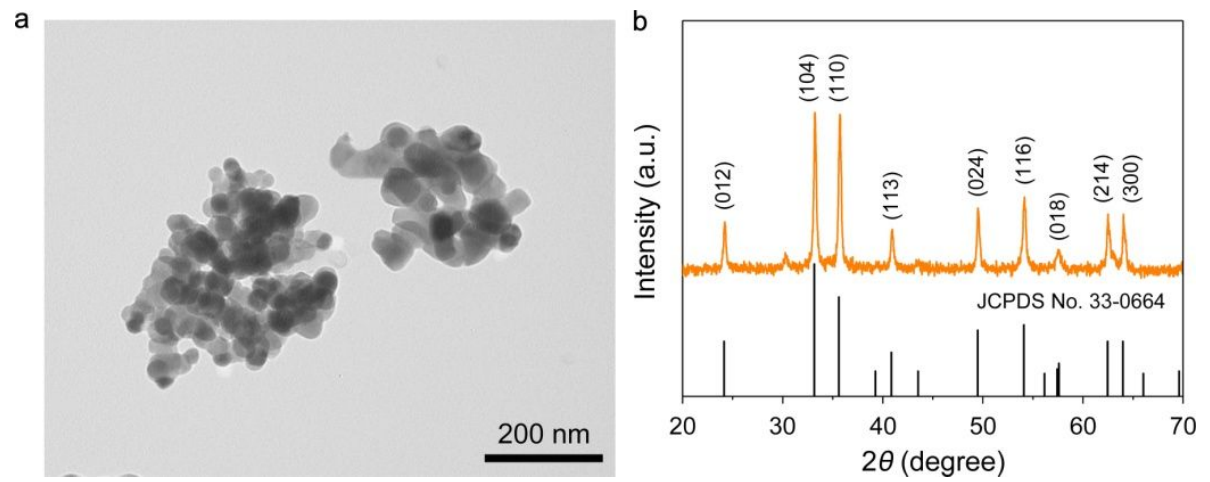

Figure S4. Morphological and structural characterizations of commercial $\mathrm{Fe}_{2} \mathrm{O}_{3}$. a, TEM image. b, XRD pattern. 
Table S1. EXAFS fitting results of $\mathrm{Fe}_{1}(\mathrm{OH})_{\mathrm{X}} / \mathrm{P}-\mathrm{C}$. Fe foil, and $\mathrm{Fe}_{2} \mathrm{O}_{3}$ were used as references.

\begin{tabular}{c|c|c|c|c|c|c}
\hline \multirow{2}{*}{ Samples } & \multicolumn{2}{|c|}{$\mathrm{Fe}-\mathrm{O}$} & \multicolumn{2}{c|}{$\mathrm{Fe}-\mathrm{Fe}$} & \multirow{2}{*}{$D . W}$. & $\Delta E_{0}(\mathrm{eV})$ \\
\cline { 2 - 6 } & $R(\AA)$ & $C N$ & $R(\AA)$ & $C N$ & & - \\
\hline \multirow{2}{*}{ Fe foil } & - & - & 2.470 & 8 & - & - \\
\hline $\mathrm{Fe}_{1}(\mathrm{OH})_{\mathrm{X}} / \mathrm{P}-\mathrm{C}$ & $1.98 \pm 0.02$ & $6.1 \pm 0.6$ & - & - & 0.004 & $14.0 \pm 3.3$ \\
\hline \multirow{2}{*}{$\mathrm{Fe}_{2} \mathrm{O}_{3}$} & 1.983 & 6 & 2.859 & 1 & & \\
& 2.062 & 6 & 2.969 & 3 & - & - \\
& 3.368 & 6 & 3.367 & 3 & & \\
\hline
\end{tabular}

$R$, distance between absorber and backscatter atoms; $C N$, coordination number; $D . W$., Debye-Waller factor; $\Delta E_{0}$, inner potential correction that accounts for the difference in the inner potential between the sample and the reference compound. 


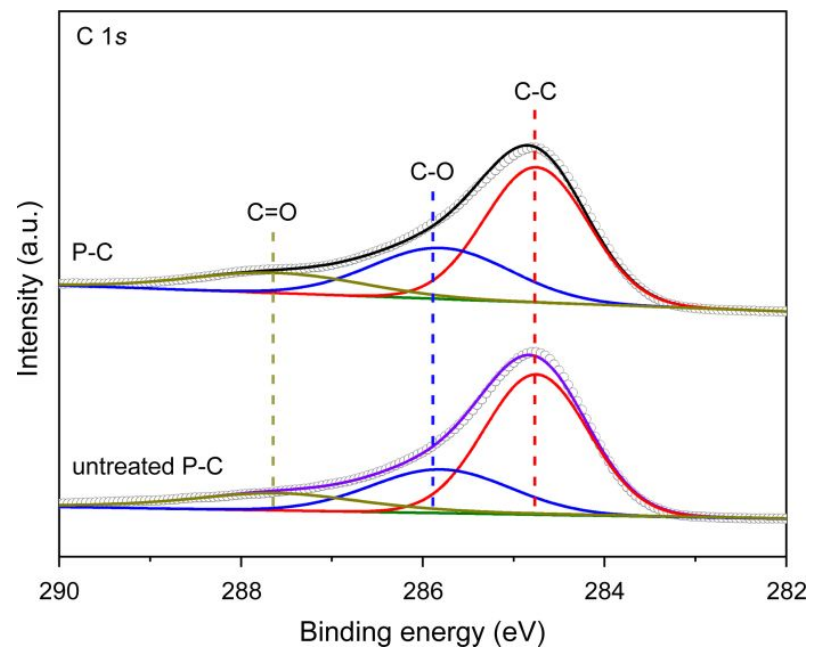

Figure S5. C 1 s X-ray photoelectron spectroscopy of P-C and untreated P-C. Three characteristic peaks were shown at 287.6, 285.8, and $284.8 \mathrm{eV}$, corresponding to $\mathrm{C}=\mathrm{O}, \mathrm{C}-\mathrm{O}$, and C-C groups, respectively. The peak area ratio of C-O to $\mathrm{C}-\mathrm{C}$ slightly increased from $41.6 \%$ to $50.5 \%$ after the electrochemical treatment, suggesting generation of more oxygenated species on P-C. 
a

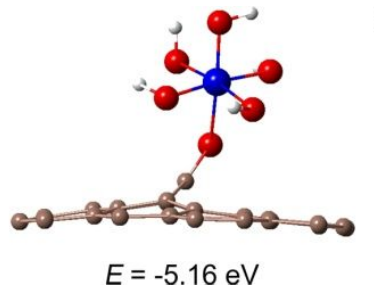

b

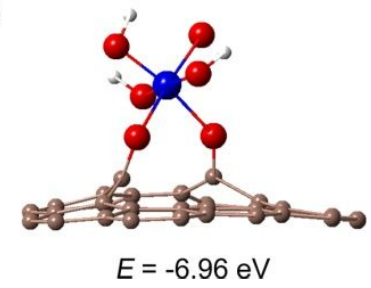

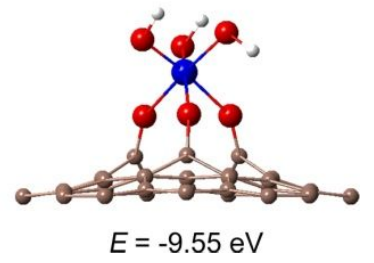

Figure S6. The formation energies $(E)$ of possible bonding modes of $\mathrm{FeO}_{6}$ on $\mathrm{P}-\mathrm{C}$ support. The blue, red, brown, and white spheres represent Fe, $\mathrm{O}, \mathrm{C}$, and $\mathrm{H}$ atoms, respectively. 


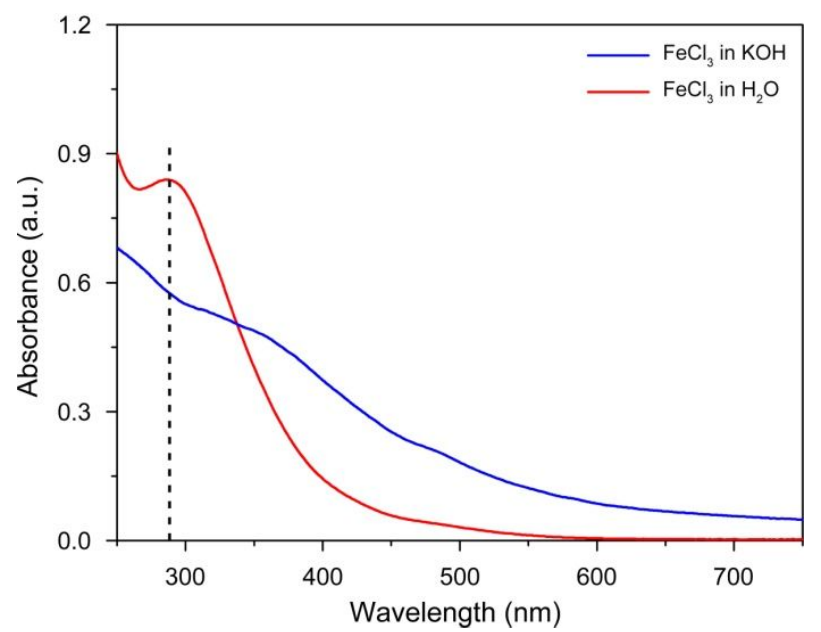

Figure S7. UV-vis spectra of aqueous solution containing $100 \boldsymbol{\mu} \mathbf{M} \mathbf{F e C l}_{3}$. The peak at $288 \mathrm{~nm}$ is ascribed to $\mathrm{Fe}^{3+}$. 


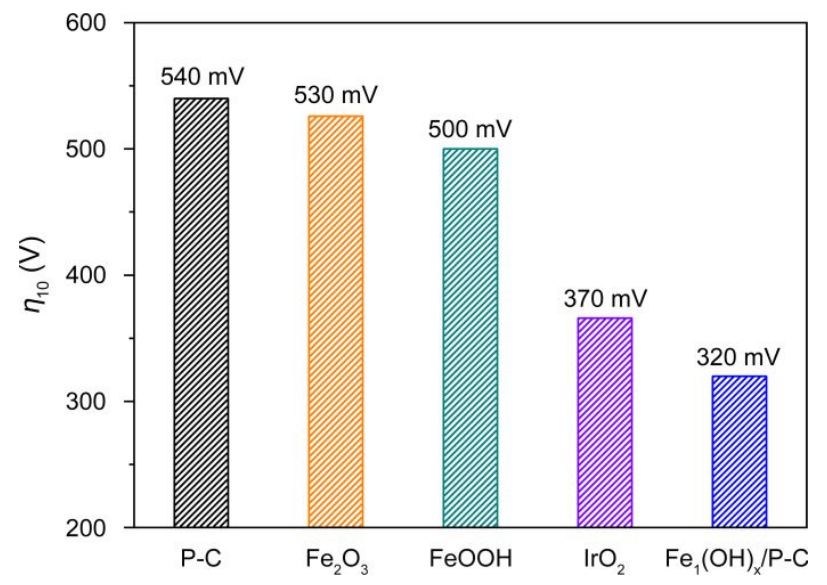

Figure S8. Overpotential at a current density of $10 \mathrm{~mA} \mathrm{~cm}$. 


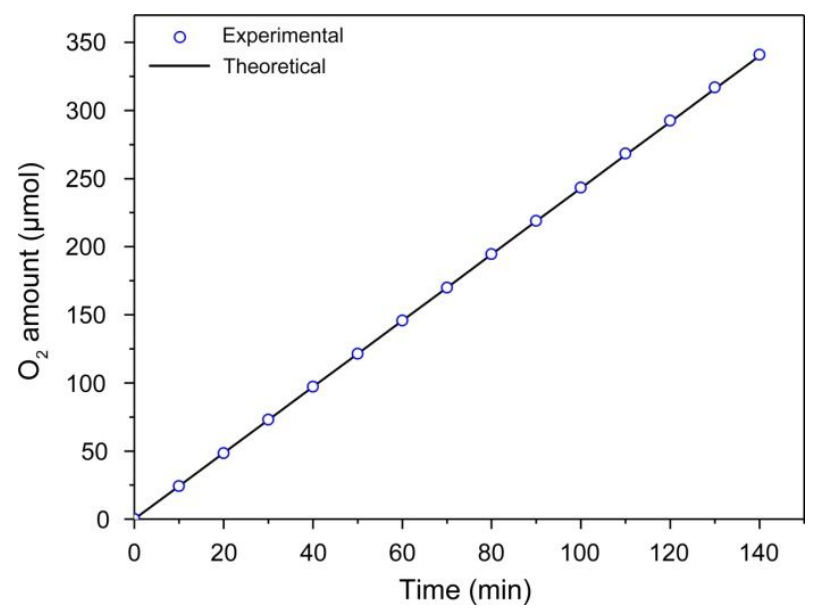

Figure S9. Faradaic efficiency of $\mathrm{Fe}_{1}(\mathrm{OH})_{\mathrm{x}} / \mathrm{P}-\mathrm{C}$ for $\mathrm{OER}$. The measurement was conducted at a current density of $10 \mathrm{~mA} \mathrm{~cm} \mathrm{~cm}^{-2}$ for $140 \mathrm{~min}$. The experimental amount of $\mathrm{O}_{2}$ production matches well with the theoretical amount, indicating $>99 \%$ Faradaic efficiency for OER. 
Table S2. Comparison of reported transitional-metal based electrocatalysts towards OER performances in alkaline electrolytes.

\begin{tabular}{|c|c|c|c|c|c|}
\hline Electrocatalysts & Electrolyte & $\begin{array}{c}\text { Overpotential } \\
(\mathrm{mV}) @ 10 \\
\mathrm{~mA} \mathrm{~cm}{ }^{-2}\end{array}$ & $\begin{array}{c}\text { Overpotential } \\
\text { (vs RHE) for } \\
\text { TOF }\end{array}$ & $\operatorname{TOF}\left(\mathrm{s}^{-1}\right)$ & Ref. \\
\hline \multirow{2}{*}{$\mathrm{Fe}_{1}(\mathrm{OH})_{\mathrm{x}} / \mathrm{P}-\mathrm{C}$} & \multirow{2}{*}{$1.0 \mathrm{M} \mathrm{КОН}$} & \multirow{2}{*}{320} & $0.3 \mathrm{~V}$ & 0.09 & \multirow{2}{*}{ This work } \\
\hline & & & $0.35 \mathrm{~V}$ & 0.62 & \\
\hline $\mathrm{FeOOH} / \mathrm{NF}$ & $1.0 \mathrm{M} \mathrm{KOH}$ & 280 & $0.35 \mathrm{~V}$ & 0.114 & $\mathrm{~S} 13$ \\
\hline $\begin{array}{l}\text { 3D iron fluoride-oxide } \\
\text { nanoporous films }\end{array}$ & $1.0 \mathrm{M} \mathrm{KOH}$ & 260 & $0.37 \mathrm{~V}$ & 0.2141 & S14 \\
\hline Fe-NHGF & \multirow{3}{*}{$1.0 \mathrm{M} \mathrm{KOH}$} & 488 & \multirow{3}{*}{$0.3 \mathrm{~V}$} & $<0.0024$ & \multirow{3}{*}{ S15 } \\
\hline Co-NHGF & & 402 & & 0.0024 & \\
\hline Ni-NHGF & & 331 & & 0.72 & \\
\hline $\mathrm{Ni}_{65} \mathrm{Fe}_{35} \mathrm{OOH}$ & $0.1 \mathrm{M} \mathrm{KOH}$ & 316 & $0.33 \mathrm{~V}$ & 0.015 & S16 \\
\hline$\alpha-\mathrm{Ni}(\mathrm{OH})_{2}$ & $0.1 \mathrm{M} \mathrm{KOH}$ & 331 & $0.35 \mathrm{~V}$ & 0.0361 & S17 \\
\hline$\delta$-FeOOH NSs/NF & $1.0 \mathrm{M} \mathrm{KOH}$ & 265 & $0.3 \mathrm{~V}$ & 0.08 & S18 \\
\hline $\mathrm{Pt}_{1} @ \mathrm{Fe}-\mathrm{N}-\mathrm{C}$ & $0.1 \mathrm{M} \mathrm{KOH}$ & 310 & - & - & S19 \\
\hline $\mathrm{Fe}_{3} \mathrm{C} @ \mathrm{NCNTs}-\mathrm{NCNFs}$ & $1.0 \mathrm{M} \mathrm{KOH}$ & 284 & - & - & S20 \\
\hline $\mathrm{Fe} / \mathrm{Fe}_{2} \mathrm{O}_{3} @ \mathrm{Fe}-\mathrm{N}-\mathrm{C}$ & $0.1 \mathrm{M} \mathrm{KOH}$ & 325 & - & - & S21 \\
\hline FeP-rGO (50:50)@CFP & $1.0 \mathrm{M} \mathrm{KOH}$ & 260 & $0.33 \mathrm{~V}$ & 0.031 & \multirow{2}{*}{ S22 } \\
\hline $\mathrm{FeP} @ \mathrm{Au}$ & $1.0 \mathrm{M} \mathrm{KOH}$ & 320 & $0.33 \mathrm{~V}$ & 0.004 & \\
\hline NiFe LDH NS & \multirow{3}{*}{$1.0 \mathrm{M} \mathrm{KOH}$} & 305 & \multirow{3}{*}{$0.3 \mathrm{~V}$} & 0.05 & \multirow{3}{*}{ S23 } \\
\hline NiCo LDH NS & & 335 & & 0.01 & \\
\hline CoCo LDH NS & & 350 & & - & \\
\hline NiFe oxyhydroxide & \multirow{2}{*}{$1.0 \mathrm{M} \mathrm{KOH}$} & 248 & $0.3 \mathrm{~V}$ & $\sim 0.01$ & \multirow{2}{*}{ S24 } \\
\hline FeCo oxyhydroxide & & 266 & $0.3 \mathrm{~V}$ & $\sim 0.01$ & \\
\hline
\end{tabular}




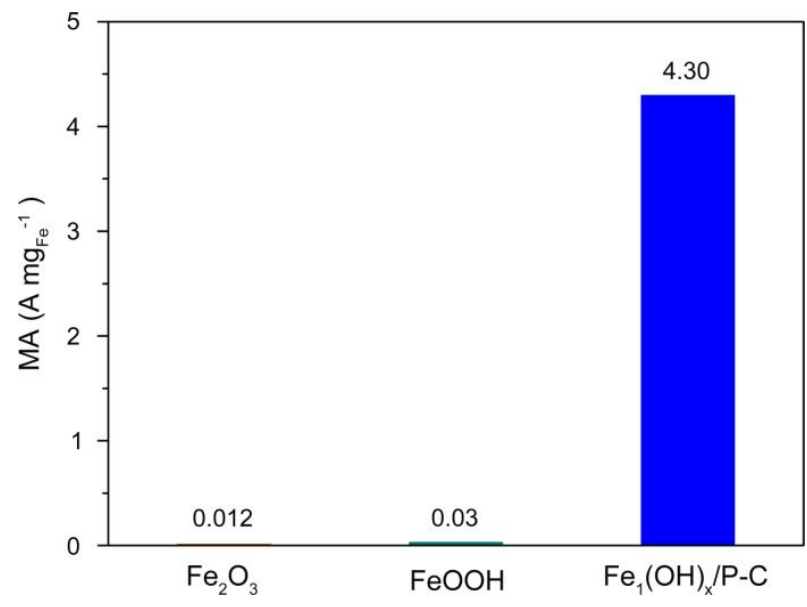

Figure S10. Mass activity (MA) of commercial $\mathrm{Fe}_{2} \mathrm{O}_{3}, \mathrm{FeOOH}$, and $\mathrm{Fe}_{1}(\mathrm{OH})_{\mathrm{x}} / \mathrm{P}-\mathrm{C}$ at an overpotential of $0.35 \mathrm{~V}$. 


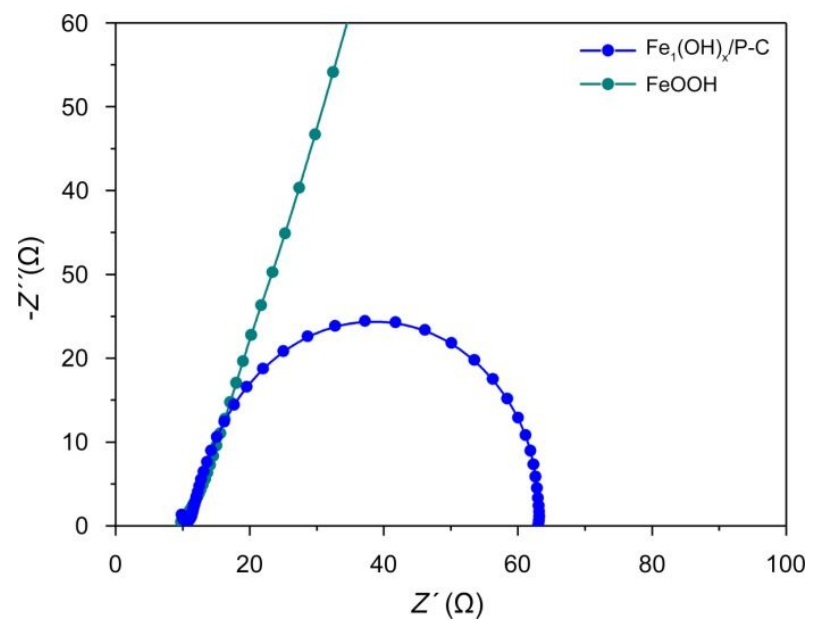

Figure S11. Electrochemical impedance spectra of $\mathrm{FeOOH}$ and $\mathrm{Fe}_{1}(\mathrm{OH})_{\mathrm{x}} / \mathrm{P}-\mathrm{C}$. 


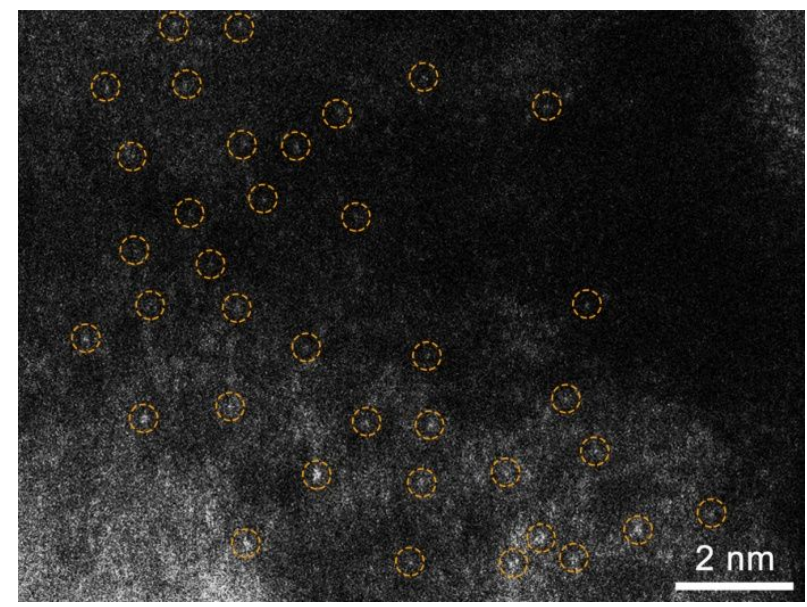

Figure S12. HAADF-STEM image of $\mathrm{Fe}_{1}(\mathrm{OH})_{\mathrm{x}} / \mathrm{P}-\mathrm{C}$ after durability test towards OER at a current density of $10 \mathrm{~mA} \mathbf{~ c m}^{-2}$ for $20 \mathrm{~h}$. The mono-dispersed Fe atoms showed no evidence of aggregation, indicating the excellent stability of $\mathrm{Fe}_{1}(\mathrm{OH})_{\mathrm{x}} / \mathrm{P}-\mathrm{C}$. 


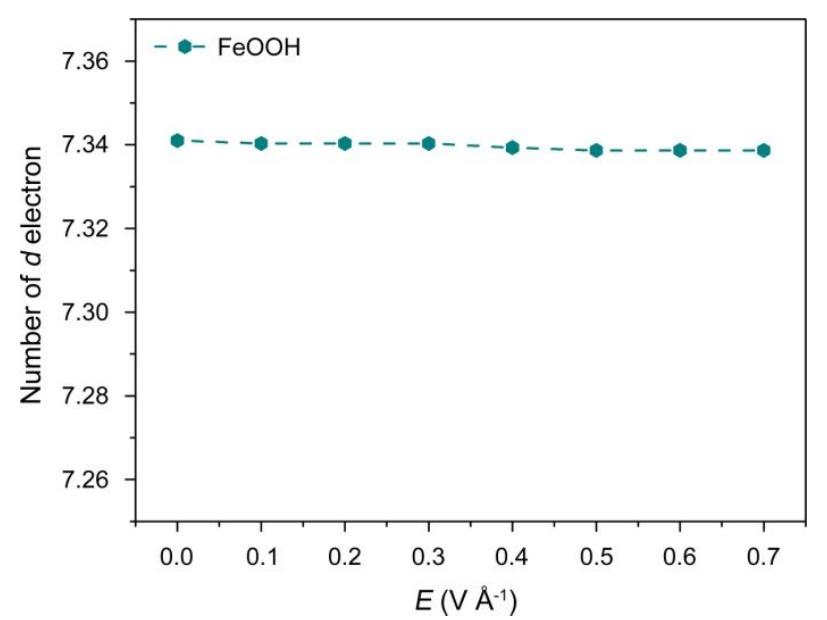

Figure S13. The number of $\boldsymbol{d}$ electrons for $\mathrm{FeOOH}$ at different potentials. 


\section{Reference}

[S1]H. Tao, C. Choi, L.-X. Ding, Z. Jiang, Z. Han, M. Jia, Q. Fan, Y. Gao, H. Wang, A. W. Robertson, S. Hong, Y. Jung, S. Liu, Z. Sun, Chem 2019, 5, 204-214.

[S2]F. Hua, X. Huang, L. Shang, Y. Can, Y. Zhao, L.-Z. Wu, C.-H. Tung, Y. Yin, T. Zhang, Angew. Chem. Int. Ed. 2016, 55, 2167-2170.

[S3]J. P. Perdew, K. Burke, M. Ernzerhof, Phys. Rev. Lett. 1996, 77, 3865-3868.

[S4]J. P. Perdew, K. Burke, Y. Wang, Phys. Rev. B 1996, 54, 16533-16539.

[S5]G. Kresse, J. Hafner, Phys. Rev. B 1993, 47, 558-561.

[S6]G. Kresse, J. Furthmüller, Phys. Rev. B 1996, 54, 11169-11186.

[S7]P. E. Blöchl, Phys. Rev. B 1994, 50, 17953-17979.

[S8]G. Kresse, D. Joubert, Phys. Rev. B 1999, 59, 1758-1775.

[S9]I. Khan, A. Hashmi, M. U. Farooq, J. Hong, ACS Appl. Mater. Interfaces 2017, 9, $35368-35375$.

[S10]S. Grimme, J. Antony, S. Ehrlich, H. Krieg, J. Chem. Phys. 2010, 132, 154104.

[S11]J. K. Nørskov, J. Rossmeisl, A. Logadottir, L. Lindqvist, J. Phys. Chem. B 2004, 108, 17886-17892.

[S12]Z. Yao, Y. Jiao, Y. Zhu, Q. Cai, A. Vasileff, L. H. Li, Y. Han, Y. Chen, S.-Z. Qiao, J. Am. Chem. Soc. 2017, 139, 3336-3339.

[S13]C. Zhang, B. Zhang, Z. Li, J. Hao, ACS Appl. Energy Mater. 2019, 2, 3343-3351.

[S14]X. Fan, Y. Liu, S. Chen, J. Shi, J. Wang, A. Fan, W. Zan, S. Li, W. A. Goddard, X.-M. Zhang, Nat. Commun. 2018, 9, 1809.

[S15]H. Fei, J. Dong, Y. Feng, C. S. Allen, C. Wan, B. Volosskiy, M. Li, Z. Zhao, Y. Wang, H.

Sun, P. An, W. Chen, Z. Guo, C. Lee, D. Chen, I. Shakir, M. Liu, T. Hu, Y. Li, A. I. Kirkland, X. Duan, Y. Huang, Nat. Catal. 2018, 1, 63-72.

[S16]M. Görlin, J. H. Stenlid, S. Koroidov, H.-Y. Wang, M. Börner, M. Shipilin, A. Kalinko, V. Murzin, O. V. Safonova, M. Nachtegaal, A. Uheida, J. Dutta, M. Bauer, A. Nilsson, O. Diaz-Morales, Nat. Commun. 2020, 11, 6181.

[S17]M. Gao, W. Sheng, Z. Zhuang, Q. Fang, S. Gu, J. Jiang, Y. Yan, J. Am. Chem. Soc. 2014, $136,7077-7084$. 
[S18]B. Liu, Y. Wang, H.-Q. Peng, R. Yang, Z. Jiang, X. Zhou, C.-S. Lee, H. Zhao, W. Zhang, Adv. Mater. 2018, 30, 1803144.

[S19]X. Zeng, J. Shui, X. Liu, Q. Liu, Y. Li, J. Shang, L. Zheng, R. Yu, Adv. Energy Mater. 2018, 8,1701345 .

[S20]Y. Zhao, J. Zhang, X. Guo, H. Fan, W. Wu, H. Liu, G. Wang, J. Mater. Chem. A 2017, 5, 19672-19679.

[S21]Y. Zang, Y. Zang, X. Zhang, R. Liu, S. Liu, G. Wang, Y. Zhang, H. Zhao, Nano Res. 2016, 9, 2123-2137.

[S22]J. Masud, S. Umapathi, N. Ashokaan, M. Nath, J. Mater. Chem. A 2016, 4, 9750-9754.

[S23]F. Song, X. Hu, Nat. Commun. 2014, 5, 4477.

[S24]B. Zhang, L. Wang, Z. Cao, S. M. Kozlov, F. P. G. Arquer, C. T. Dinh, J. Li, Z. Wang, X. Zheng, L. Zhang, Y. Wen, O. Voznyy, R. Comin, P. D. Luna, T. Regier, W. Bi, E. E. Alp, C.-W. Pao, L. Zheng, Y. Hu, Y. Ji, Y. Li, Y. Zhang, L. Cavallo, H. Peng, E. H. Sargent, Nat. Catal. 2020, 3, 958-992. 